\title{
Current Insights
}

\section{Sarah L. Eddy*}

Florida International University, Miami, FL 33199

\begin{abstract}
The Current Insights feature is designed to introduce life science educators and researchers to current articles of interest in other social science and education journals. In this installment, I highlight three recent studies from the fields of psychology and higher education that can inform practices in the life sciences. The first is a synthesis paper that builds a unifying framework for the diverse activities that fall under the umbrella term "active learning." This paper emphasizes a novel aspect of the active-learning classroom: student agency. The second paper employs an underutilized framework in biology education research, quantitative critical theory, to explore why faculty-student interactions may not be universally beneficial. The third paper explores how valuing relationships can keep first-generation college students from reaching out for help when they need it. Together, these last two papers help researchers understand the perceived costs and benefits of seeking help from faculty.
\end{abstract}

\section{A FRAMEWORK FOR ACTIVE LEARNING THAT EMPHASIZES AGENCY}

Lombardi, D., Shipley, T. F., \& Astronomy Team, Biology Team, Chemistry Team, Engineering Team, Geography Team, Geoscience Team, and Physics Team. (2021). The curious construct of active learning. Psychological Science in the Public Interest, 22(1), 8-43.

Active learning is a well-established buzzword in discipline-based education research (DBER) communities. However, what active learning means to one person may not be what it means to another, and this gap can cause problems in communication and in research to optimize student learning. In this paper, Lombardi and colleagues have synthesized the research literature on active learning in an attempt to create a unifying framework. Ultimately, they center an aspect of active-learning classrooms that has not been highlighted much in biology education research: student agency.

Lombardi and colleagues embraced an interdisciplinary approach to characterizing active learning. They brought together experts from psychology and across multiple science, technology, engineering, and mathematics (STEM) disciplines (astronomy, biology, chemistry, engineering, geoscience, and physics). The first step in their synthesis was for a team of DBER researchers in each discipline to write white papers reviewing the use and assessment of active learning in their fields. These researchers also wrote an initial synthesis definition of active learning based on the work done in their fields. These initial summaries helped the authors understand the variation in active-learning practices across the disciplines. For example, one axis of variation was the skills that students were learning through active learning. Some STEM disciplines rely primarily on observations of the world, while others rely primarily on experimental science that can isolate and evaluate the impact of single variables. The differences in skills emphasized in these disciplines meant active learning was carried out in different ways in their classrooms. An interdisciplinary team of psychologists read the white papers and worked with the DBER teams to interpret their findings through the lens of the psychology of learning, and together they built a consensus model and working definition for active learning.
CBE Life Sci Educ December 1, 2021 20:fe6 DOI:10.1187/cbe.21-09-0264

This feature is designed to point CBE-Life Sciences Education readers to current or noteworthy articles for life science educators and education researchers. We invite readers to suggest current themes or articles of interest in life science education as well as influential papers published in the more distant past or in the broader field of education research to be featured in Current Insights. Please send any suggestions to Julia.Gouvea@tufts.edu.

*Address correspondence to: Sarah L. Eddy (seddy@fiu.edu).

() 2021 S. L. Eddy. CBE-Life Sciences Education () 2021 The American Society for Cell Biology. This article is distributed by The American Society for Cell Biology under license from the author(s). It is available to the public under an Attribution-Noncommercial-Share Alike 3.0 Unported Creative Commons License (http://creativecommons.org/ licenses/by-nc-sa/3.0)

"ASCB®" and "The American Society for Cell Biology $\circledR^{\prime \prime}$ are registered trademarks of The American Society for Cell Biology. 
Their full characterization of active learning, which they call a "construction-of-understanding ecosystem," takes a systems approach and involves both the content of science and the actors present in classrooms. It can be applied to multiple formal education contexts, including lecture courses and labs. The content of science they focus on includes domain practices, data, models, and direct experiences. These can be used for sense making by teachers or students. In a lecture-based class, the teacher makes meaning of the science and transmits this processed meaning to the students. In an active-learning class, the students work directly with the content of science to make sense of it themselves, with peers, and in dialogue with the instructor (who acts as a facilitator).

The core element that these authors suggested distinguished active-learning classes from lecture-based classes is agency; specifically, who in the room has agency to engage in sense making with the content. As described in the paper, authors drew their conception of agency from Bandura (2001): "To be an agent is to intentionally make things happen by one's actions.... The core features of agency [intentionality, forethought, self-reactiveness, and self-reflectiveness] enable people to play a part in their self-development." Although agency in sense making is possible in lecture classrooms, it is explicitly built into active-learning methods. As reviewed in the paper, agency has been shown in many psychological studies to lead to deeper cognitive, behavioral, and emotional engagement that could help explain the learning benefits of active learning. The authors also warn that careful scaffolding of content by instructors is necessary to help students be successful in these agentic classes.

This paper nicely highlights the values of bringing diverse perspectives to bear on a question and, in this case, elucidates a mechanism (agency) for explaining why the diverse practices collected under the term "active learning" may be effective.

\section{MORE INTERACTIONS WITH FACULTY ARE NOT BENEFICIAL FOR EVERYONE}

Park, J. J., Kim, Y. K., Salazar, C., \& Eagan, M. K. (2020, June 11). Racial discrimination and student-faculty interaction in STEM: Probing the mechanisms influencing inequality. Journal of Diversity in Higher Education. Advance online publication. https://doi.org/10.1037/dhe0000224

As instructors, we often assume students benefit from interactions with us. In this paper, Park and colleagues challenge this assumption. They hypothesize that student-faculty interactions also have the potential to harm students, specifically students of color who may experience discrimination during these interactions. These researchers use the lens of quantitative critical theory, or QuantCrit, to take a more nuanced approach to characterize for whom interactions with faculty produce benefits and why this may vary across student racial groups.

As described in the introduction, QuantCrit combines critical race theory with quantitative research to challenge the deficit model that can be prevalent, intentionally or not, in quantitative research and to challenge the idea of the objectivity of numbers. Specifically in this study, researchers challenge common deficit-based explanations for why students of color do not do as well in STEM: for example, their lack of ability in STEM, or that they do not interact enough with faculty to get the help they need. They hypothesize instead that discrimination from faculty during student-faculty interactions may counter the performance benefits that students of color could receive from these interactions. White students who do not encounter such discrimination thus stand to benefit more from these interactions.

Researchers administered a survey to students across 27 institutions at five time points. They collected race, family income, high school math grade point average (GPA), and gender data at the beginning of students' first year at college. At the end of the first year of college, they measured students' self-reported interactions with faculty, using questions about help-seeking behaviors. In year 3, students completed questions about racial discrimination experienced from faculty. Finally, at the end of their fourth year in college, students reported their academic satisfaction and their college GPA. The final sample for the study contained 778 undergraduate STEM majors (25.7\% White, 25.2\% Black, 22.6\% Hispanic, and 26.5\% Asian American).

Researchers initially ran a structural equation model (SEM) that included all study participants. SEMs allow you to explore the relationships between your variables as well as the relationship of all your variables to the outcome variable. This model painted a complex picture of the role of faculty-student interactions in academic performance. Researchers found that Black students reported more interactions with faculty than any other students. Increased interactions increased academic satisfaction, and, in turn, increased academic satisfaction predicted an increase in GPA. However, students who interacted more with faculty also experienced more racial discrimination, and racial discrimination reduced college GPA. Combining these two pathways influencing GPA, experiencing discrimination reduced the positive effect of student-faculty interactions on GPA (through academic satisfaction) by $39 \%$. So, experiences of discrimination do reduce the benefits of faculty-student interactions.

Researchers then ran a multigroup SEM in which they calculated a model for students in each racial group and contrasted them. They found several important patterns that supported their hypothesis that faculty discrimination limits the positive effects of faculty-student interactions. First, they found that the more Black students interacted with faculty, the more discrimination they reported. This relationship was not significant for any other racial group. Second, only white students experienced a significant positive effect on GPA from increased faculty-student interactions. Finally, academic satisfaction did increase with increased faculty-student interactions for all students, but academic satisfaction was not related to college GPA for white or Black students.

In summary, the observed patterns of faculty-student interactions benefiting students, as measured by college GPA in this study, only held for white students. Although Black students report more interactions with faculty, these interactions led to increased experiences of discrimination that were related to lower GPA. This suggests structural issues of racism are holding Black students back from reaping the benefits white students receive from interacting with their faculty. 
CHALLENGES FOR HELP-SEEKING BY FIRST-GENERATION STUDENTS: VALUING INTERDEPENDENCE MEANS BEING SELF-RELIANT

Chang, J., Wang, S. W., Mancini, C., McGrath-Mahrer, B., \& Orama de Jesus, S. (2020). The complexity of cultural mismatch in higher education: Norms affecting first-generation college students' coping and help-seeking behaviors. Cultural Diversity and Ethnic Minority Psychology, 26(3), 280.

Student help-seeking behaviors can seem a little mysterious. Instructors hold office hours, and it can feel as though few students take advantage of this offered help, even after a challenging class session or exam. In this paper, Chang and colleagues explore patterns in help-seeking behaviors of first-generation college students. They take a cultural approach to examine the potential role of a cultural mismatch between norms of higher education and norms in working-class contexts on the strategies first-generation students use to get assistance when they need it.

Chang and colleagues conducted group interviews with 60 first-generation college students at one university (51\% of whom were also students of color) about their perceptions of the match between college and their family culture, as well as their concerns about sharing personal challenges with others, and what motivates these concerns. Researchers used grounded theory to develop codes to analyze these interviews.

In the interviews, participants described a cultural mismatch between the university and their families. Researchers characterized the two conflicting norms as self-expression (valued by the university) and self-sufficiency (valued by their families). The norm of self-expression promoted "freedom of expression, personal exploration, and the pursuit of one's interests." This norm included advocating for the help one needs when one needs it. The norm of self-sufficiency was the "ability to provide for oneself without assistance ... from ... other people." Participants described resolving this potential conflict in norms by personally embracing both. However, there was variation in which of the two was the more dominant norm: participants of color emphasized the importance of self-sufficiency (the family value), whereas white participants focused more on self-expression (the university value).
When it came to coping with challenges, most participants employed a strategy of self-reliance that related more to the norm of self-sufficiency. This strategy involved working through a problem themselves rather than asking for help. This coping mechanism led to reduced use of available social supports. When participants described reaching out to friends or family for support, it was more for companionship and not for direct assistance resolving their problem. In fact, participants said they often did not share that a problem even existed with the people they sought out. When participants did decide to reach out, they were very selective about persons with whom they did share their challenges. They deliberately sought support from those who could understand their specific problem and from whom that support felt less risky. This was not usually their friends and family. Participants overall described a lack of knowledgeable mentors they felt comfortable reaching out to about their problems.

Researchers probed the reasons participants did not share their problems with others and found they revolved around relational concerns. It seemed that the importance of relationships to participants meant they chose not to risk changing those relationships by sharing their problems. The specific concerns participants described about disclosure included not wanting to be a burden to others, fear that sharing would change their relationship in a negative way (i.e., they would be judged negatively or pitied), or that sharing would just add to the problem. In addition, participants of color shared additional concerns including fear of inviting criticism from others, wanting to avoid loss of face in a relationship, and maintaining harmonious relationships generally.

In summary, this research identified one of the challenges for help seeking among first-generation students: the perceived risk that it may negatively impact a valued relationship. They would rather work through the problem themselves than risk their relationships. Those working with first-generation college students should consider how to incorporate this value of self-sufficiency when offering support.

\section{REFERENCE}

Bandura, A. (2001). Social cognitive theory: An agentic perspective. Annual Review of Psychology, 52, 1-26. 